\title{
Weak Signals and Mind-Sets of Consumers: The Case of
} Milk

\author{
Attila Gere ${ }^{1}$, Ryan Zemel ${ }^{2}$, Petraq Papajorgii ${ }^{3}$ and Howard Moskowitz ${ }^{4}$ \\ 1. Szent István University, Villányiút 29-43, H-1118 Budapest, Hungary \\ 2. Independent Researcher, Downers Grove, IL 60515, USA \\ 3. University of New York Tirana, Rruga "Kodra e Diellit", Selitë, Tirana 1046, Albania \\ 4. Mind Genomics Advisors, 11 Sherman Ave, White Plains, NY 10605, USA
}

\begin{abstract}
We present results from one of a set of studies run in the early 2000's, which looked at weak signals in terms of what consumers wanted. That study, on milk, revealed four distinct mind-sets, groups of respondents who thought alike. These are: S1 Traditional + Health, S2 Traditional + Healthful Ingredients, S3 Traditional + Indulgent, S4 Listens to Authority, respectively. At that time the focus on foods as the source of health and wellness was just beginning. We show how to discover hitherto new, unexpected mind-sets of respondents, using experimental design of messaging, coupled with deconstruction of these messages by regression, and followed by clustering. We suggest that this approach to messaging consumers using experimental design provides a powerful method to uncover emerging mind-sets in the consumer population.
\end{abstract}

Key words: Horizontal segmentation, dairy products, consumer segmentation, big mind, mind genomics, conjoint analysis.

\section{Introduction}

Consumer preferences for food continually change, evolving as a function of the Zeitgeist regarding tastes (what people like), health (what people think is important to maintain health), social pressure (what is considered to be attractive), and of course economics (what can be afforded), and finally availability (what stores sell). It is also a truism that consumers often do not know what they like. Despite the increasing prevalence of questionnaires for "feedback", the reality is that people do not know what they have not experienced. For example, author Moskowitz, well known for his work on so-called "horizontal" segmentation (sensory-preference segmentation), has averred from his work that people did not know what they wanted when evaluating actual prototypes for tomato-based pasta sauce [1].

The problem of what people want but cannot

Corresponding author: Howard Moskowitz, Ph.D., research fields: consumer segmentation, mind genomics. express, is part of a larger topic, "weak signals". These are trends in the environment that cannot be easily discerned. These trends, these weak signals, may be confused with the ever-present "noise" in consumer behavior. When the researcher observes variation across people in the studies of food preference, the question arises regarding the nature of this variation. Is the variation simple the aforementioned randomness which inheres in the data from people, or does it suggest different groups, showing different preferences, the aforementioned sensory segments [2]?

We focus our work here on milk. The data come from a series of studies run around 2002, with the notion of looking at the mind of the consumer. Our vantage point now is 16 years later. The question is whether the structure of the mind has changed. We will look at what ideas or elements are important in that early work, and then divide the respondents by the pattern of the ideas which are important. As we will see, the patterns emerging in 2002 remain with us, 
more than a decade and a half later.

Milk is an especially interesting topic. In the United States culture, milk occupies a special position, almost a holy one. Milk is considered to be very important for child development, to strengthen bones and to help the child grow. Milk is also considered to be the source of many nutrients, but it is the traditional ones of calcium and vitamin D3 that are the mainstays when people are asked about milk's nutritional value. There are negatives involving milk as well, such as fat, and lactose intolerance.

When we selected milk in the early study, it was among a larger series of products which were considered "healthful". Milk consumption is influenced by several factors, such as beliefs, attitudes, and sensory attributes [3, 4]. These factors, however, are hard to predict based on socio-demographic data. More advanced methods are needed. It has also been reported that "when product information was given, both liking and rated likelihood of buying increased for the type of sample towards which subjects had a more generally positive attitude” [5]. In a 2002 study, it was suggested that deeper knowledge was needed to understand different consumer segments about organic milk products in order to broadcast the proper messages to the proper consumer groups [6]. Additionally, it has been identified that consumer opinion will gradually prevail about organic food products and that agricultural farming systems will have to adjust to more extensive lower input farming approaches [7]. The same patterns were observed later regarding the importance of personal norms. When buying organic milk products, people reporting strong personal norms use the labels "organic production”, the "EU-BIO-Label" and "ingredients" as additional criteria during their decision process, which also highlights the importance of mind-set-based segmentation [8].

The latest results show a significant effect of country of origin on consumer decisions when buying organic milk products. It has also been identified that domestic organic products are preferred over products from a geographically distant country [9].

We now present the data, looking in retrospect at what was important to consumers. As we shall see, the key learning is not from the total panel, but from the discovery of so-called mind-set segments, individuals with different preference patterns in terms of the messages to which they respond most strongly. Those patterns remain with us today. Perhaps the distribution of individuals across these segments change, but we see recognizable groupings of people which both make sense, and "cover the space" or the range of different ways of looking at milk.

\section{Method}

The approach has been discussed previous in a number of books and papers (such as Refs. [10-12]). The method follows this choreography:

(1) Select an experimental design. The design specifies the questions to be asked. Table 1 shows the four questions.

(2) For each question, select nine answers. The answers should be short, single-minded, and be relevant to the topic.

(3) Create a basic experimental design, comprising 2-5 answers, with no more than one answer per question. Ensure that each answer appears equally often. The experimental design comprises 60 combinations. The experimental design ensures that the 36 answers appear in a statistically independent fashion, allowing the data (rating of the different combinations, along with the underlying experimental design) to be analyzed by OLS (ordinary least-squares regression). The approach was originally created to understand how people make decisions, but had since been applied extensively to many aspects of consumer behavior. In its original, the method was called “conjoint measurement”, a name which remains today, a half century later [13].

(4) Create 200 different permutations of these basic experimental design, referenced above in Step 3. The 
Table 1 The four questions and the nine answers per question, from which the vignettes are constructed.

\begin{tabular}{|c|c|}
\hline & Question A-What are the general benefits of the product? \\
\hline A1 & Healthy drinking that tastes great \\
\hline A2 & A tall glass of delicious, ice cold milk, right from the fridge \\
\hline A3 & Indulgent flavors like rich and creamy chocolate and cookies in cream \\
\hline A4 & Incredibly smooth and creamy \\
\hline A5 & Crisp, light and refreshing \\
\hline A6 & A full line of fresh milk \\
\hline A7 & Skim plus with $37 \%$ more protein \\
\hline A8 & All natural ... no artificial flavors, no preservatives \\
\hline \multirow[t]{2}{*}{ A9 } & $100 \%$ organic \\
\hline & Question B-What are the nutritional benefits of the milk? \\
\hline B1 & Provides essential nutrients for bone health, including calcium and vitamin D \\
\hline B2 & Provides essential minerals your body needs, including potassium, magnesium, and zinc \\
\hline B3 & With ingredients that restore and maintain a healthy balance in your digestive system \\
\hline B4 & With important micronutrients that enhance the body’s immune function \\
\hline B5 & With inulin ... known to improve calcium absorption and improve digestion \\
\hline B6 & Contains the essential nutrient choline ... shown to improve memory and learning \\
\hline B7 & Contains essential omega-3 fatty acids, which may reduce your risk of heart disease \\
\hline B8 & An important natural source of protein \\
\hline \multirow[t]{2}{*}{ B9 } & Made with plant sterol esters ... clinically proven to lower cholesterol \\
\hline & Question C-What are the emotional benefits to you? \\
\hline C1 & A quick and easy way to get the nutrition you want \\
\hline $\mathrm{C} 2$ & A beverage you feel good about serving your family \\
\hline C3 & Fills that empty spot in you ... just when you want it \\
\hline $\mathrm{C} 4$ & Such pleasure ... knowing you are drinking something healthy \\
\hline C5 & Calms you down ... just what you need when you are feeling stressed \\
\hline C6 & Even better for you than you thought \\
\hline C7 & Builds and maintains strong bones \\
\hline C8 & As part of a low fat, low cholesterol diet, may reduce the risk of some forms of cancer \\
\hline \multirow[t]{2}{*}{ C9 } & May reduce your risk of high blood pressure and stroke \\
\hline & Question D—What is the authority (brand, endorsement)? \\
\hline D1 & From your favorite local dairy \\
\hline D2 & From dean's \\
\hline D3 & From Lactaid \\
\hline D4 & From organic valley \\
\hline D5 & Endorsed by the American Heart Association \\
\hline D6 & Endorsed by the American Diabetes Association \\
\hline D7 & Endorsed by the American Dietetic Association \\
\hline D8 & Recommended by your doctor \\
\hline D9 & Recommended by nutritionists and dieticians \\
\hline
\end{tabular}

permutations are created by changing the mapping of the answers to the variables. Thus, in one experimental design Answer A1 may be replaced by Answer A2, and so forth. This permutation maintains the mathematical properties of the experimental design, but ensures that each respondent will evaluate a different set of combinations [14].

(5) Create the rating question. It is the rating question which allows the respondent to convey his or her impression of the entire vignette. The rating question is: How interested are you in this Milk? 
(6) Create an orientation page, introducing the respondent to the task. The orientation page instructs the respondent to reach the entire combination i.e., vignette, as a single idea, and to the rate the combination on the foregoing rating scale. There may be different types of rating scales, depending upon the particular focus of the study.

\section{Executing the Study}

(1) The study is run with respondents who have agreed to participate in these types of Internet-based studies. At the time of the study (around 2002), it was quite easy to get respondents. We worked with a Canadian research company, Open Venue Ltd., which offered a sweepstakes prize for the participants. A total of 248 respondents participated. Table 2 presents the breakout of the 248 respondents on geo-demographics.

(2) Respondents were presented with the orientation page, and then evaluated the 60 vignettes. The evaluation took approximately 15 minutes. After the evaluation, the respondents complete a self-profiling classification question, dealing with who the respondent is, and what the respondent believes in terms of health.

(3) The ratings assigned by each respondent are converted to a binary scale, with ratings of 1-6 converted to 0 , and ratings of 7-9 converted to 100 . A small random number $\left(<10^{-5}\right)$ is added to the transformed data to ensure that the OLS regression will run, even when a respondent confines his or her ratings to the low end of the scale (1-6, all converted to 0 ), or confines his or her ratings to the high end of the scale (7-9, all converted to 100).

(4) The individual models are average by the relevant subgroups. In this presentation we show the results by total panel, and then by emergent mind-set segmentation.

\section{Results}

Table 3 shows the summary data, from the average of 248 respondents. Each respondent generated a model with 37 parameters, first an additive constant, and then 36 coefficients, one coefficient for each answer or element, respectively. Recall that each respondent saw 60 combinations, the vignettes, and never saw the answers or elements alone. The experimental design enables us to estimate the contribution of each element to the binary 0/100 scale.

(1) The additive constant represents the estimated likelihood of a respondent assigning a rating of 7-9 in the absence of the elements. The additive constant is a purely estimated parameter. In our case, the constant is 44, suggesting that without any information, almost half of the respondents, i.e., $44 \%$ would be interested in the milk.

(2) Table 2 shows (third column) that the 44 is simply an average and that across the different groups of respondents in the population we have.

(3) We have shaded and bolded cells with elements scoring +7.51 or higher. With a typical standard error around 3.5-4.0, a coefficient of +7.51 approaches statistical significance.

(4) Previous studies with this method of experimental design using mixtures of messages suggest that coefficients of 10 or higher signal an important idea, and coefficients of 5-10 signal a relevant, but not as important idea. Our data from the total panel suggest only one important idea, A2, a word picture of milk: A tall glass of delicious, ice cold milk, right from the fridge.

(5) Five elements score between 5 and 10, the level deemed to be relevant, but not particularly important.

Healthy drinking that tastes great;

Provides essential nutrients for bone health, including calcium and vitamin $D$;

May reduce your risk of high blood pressure and stroke;

Builds and maintains strong bones;

As part of a low fat, low cholesterol diet, may reduce the risk of some forms of cancer.

(6) Two elements score the lowest. Both deal with 
Table 2 The panel composition (base size), and the average additive constant from the model relating the presence/absence of the elements to the binary value of "interest". The binary value emerges after the transformation of the ratings, the original 1-9 scale, to the binary scale (1-6 transformed to 0; 7-9 transformed to 100). Subgroups comprising fewer than 10 respondents have been eliminated from the table.

\begin{tabular}{|c|c|c|}
\hline & Base size & Constant \\
\hline Total sample & 248 & 44 \\
\hline Gender male & 62 & 41 \\
\hline Gender female & 186 & 46 \\
\hline Age $20-29$ & 47 & 30 \\
\hline Age 30-39 & 65 & 47 \\
\hline Age 40-49 & 57 & 41 \\
\hline Age 50-59 & 51 & 55 \\
\hline Age 60-69 & 19 & 50 \\
\hline Marital—single & 48 & 43 \\
\hline Marital-married & 154 & 42 \\
\hline Marital—divorced & 41 & 52 \\
\hline Children 0 & 130 & 41 \\
\hline Children 1 & 47 & 54 \\
\hline Children 2 & 44 & 44 \\
\hline Children 3 & 14 & 36 \\
\hline Lives-Middle Atlantic States (NY,NJ, PA) & 35 & 47 \\
\hline Lives-South Atlantic States (DE, MD, DC, WV, VA, NC, SC, GA, FL) & 41 & 43 \\
\hline Lives—East North Central States (WI, IL, MI, IN, OH) & 35 & 49 \\
\hline Lives_East South Central States (KY, TN, MS, AL) & 16 & 36 \\
\hline Lives-West North Central States (ND, SD, NE, KS, MN, IA, MO) & 19 & 39 \\
\hline Lives-West South Central States (TX, OK, AR, LA) & 23 & 46 \\
\hline Lives-Mountain States (MT, WY, ID, CO, UT, AZ, NM, NV) & 16 & 50 \\
\hline Lives-Pacific States (WA, OR, CA, AK, HI) & 35 & 51 \\
\hline Lives-Outside the US & 19 & 35 \\
\hline Education-Some high school & 10 & 43 \\
\hline Education—High School graduate & 64 & 53 \\
\hline Education-Technical school & 18 & 43 \\
\hline Education-Some College & 67 & 48 \\
\hline Education—Associates Degree & 26 & 48 \\
\hline Education-Bachelors degree (4 year college) & 42 & 32 \\
\hline Education—Post graduate degree (Masters or Doctorate) & 21 & 27 \\
\hline Income--Under $\$ 25,000$ & 67 & 47 \\
\hline Income- $\$ 25,000-\$ 34,999$ & 39 & 52 \\
\hline Income- $\$ 35,000-\$ 49,999$ & 39 & 32 \\
\hline Income- $\$ 50,000-\$ 74,999$ & 43 & 39 \\
\hline Income- $\$ 75,000-\$ 99,999$ & 21 & 44 \\
\hline Income-Prefer not to say & 31 & 56 \\
\hline Mind—set segment SegD1 & 111 & 48 \\
\hline Mind-set segment SegD3 & 51 & 25 \\
\hline Mind—set segment SegD2 & 49 & 43 \\
\hline Mind—set segment SegD4 & 37 & 61 \\
\hline
\end{tabular}


specifics, which, perhaps in the early 2000's, were irrelevant, but would become important later on, in today's world:

From Lactaid;

Made with plant sterol esters ... clinically proven to lower cholesterol.

(7) From Table 3 we do a mixture of different ideas doing well, and two ideas doing poorly. There is no sense of a homogeneous population. We will discover that homogeneity in the next section when we divide our 248 respondents into non-overlapping groups, based upon the pattern of their coefficients.

\section{Making Sense of Individual Difference by Segmenting Respondents Using Patterns of Coefficients}

During the past twenty years, the notion of mind-set segmentation has become increasingly clearer. Segmentation refers to the rubric of dividing people by the pattern of their responses. Traditional segmentation divides people by the patterns of people reflected in "Who they are" (e.g., age, gender, income, social class), by the patterns reflect in "What they believe" (so-called psychographic segmentation), and more recently by the pattern of "What they do" electronically when they use the internet say for shopping.

The researcher uses segmentation to understand the differences between groups, and among people. The ingoing belief is that people who are different, based on the segmentation, should respond differently, and predictability to messaging. That is, there is a belief, not often expressed directly, that "somehow", for instance, males different from females in terms of the specific messages to which they respond. Fig. 1 shows that this hypothesis is simply not valid for the case of milk. The scatter plot suggests a linear relation, although at the bottom, the elements which do not appeal to males may differ from the elements which do not appeal to females. Nonetheless, the correlation is high, +0.81 across 36 coefficients.
An alternative method divides respondents by focusing on how the respondents either resemble each other or differ from each other, based upon the pattern of coefficients for the particular study. This approach to clustering respondents is known by the general term "Mind Genomics". The term uses the word "Genomics" in a metaphoric sense, rather than in an exact sense. The organizing principle underlying Mind Genomics is that in any specific topic that can be "dimensionalized" through descriptions, such as milk in this study, there exist groups of people, or better groups of ideas, which are relatively homogeneous. Rather than a person responding strongly to a collection of seemingly unrelated messages, the segmentation into mind-sets reveals groups of individuals who respond to a limited set of related messages.

An example of the segmentation appears in Table 4. The segmentation, so-called k-means segmentation divides people by the pattern of their coefficients. People with similar patterns are assigned to the same mind-set. People with dissimilar patterns are assigned to different mind-sets. The objective of the clustering or segmentation is to emerge with as few mind-sets as possible within a topic area (parsimony), with each mind-set being "interpretable", i.e., making sense interpretability.

For the milk data, either a 3-segment or a 4-segment solution makes sense. The 4-segment solution reveals two groups which were somewhat similar. Segment D1 wants tradition and health, with the health being the calcium and vitamin D for which milk is known. Segment D2, one fifth of the sample, wants the same health, but is conscious of, and responsive to, the healthful essentials of milk.

Segment D3 comprises those respondents who want indulgence, specifically flavors and taste. Segment D4 comprises those respondents who respond to authority.

Fig. 2 shows a set of pairwise scatterplots, which in turn suggest that these four segments do not show correlated coefficients, in the way that the two genders 
Table 3 Performance of the 36 elements based on the data from the total panel. The coefficients come from the model using the "transformed ratings", so that all ratings were transformed to a binary scale (1-6 transformed to 0, 7-9 transformed to 100). The table is sorted in rank order of the value of the coefficients.

\begin{tabular}{|c|c|c|}
\hline & & Total \\
\hline & Base size & 248 \\
\hline & Constant & 44 \\
\hline A2 & A tall glass of delicious, ice cold milk, right from the fridge & 15 \\
\hline A1 & Healthy drinking that tastes great & 7 \\
\hline B1 & Provides essential nutrients for bone health, including calcium and vitamin D & 7 \\
\hline C9 & May reduce your risk of high blood pressure and stroke & 7 \\
\hline C7 & Builds and maintains strong bones & 6 \\
\hline C8 & As part of a low fat, low cholesterol diet, may reduce the risk of some forms of cancer & 5 \\
\hline D5 & Endorsed by the American Heart Association & 4 \\
\hline D6 & Endorsed by the American Diabetes Association & 4 \\
\hline A6 & A full line of fresh milk & 3 \\
\hline A8 & All natural ... no artificial flavors, no preservatives & 3 \\
\hline B8 & An important natural source of protein & 3 \\
\hline C1 & A quick and easy way to get the nutrition you want & 3 \\
\hline C4 & Such pleasure ... knowing you are drinking something healthy & 3 \\
\hline D7 & Endorsed by the American Dietetic Association & 3 \\
\hline D8 & Recommended by your doctor & 3 \\
\hline A4 & Incredibly smooth and creamy & 2 \\
\hline B2 & Provides essential minerals your body needs, including potassium, magnesium, and zinc & 2 \\
\hline B3 & With ingredients that restore and maintain a healthy balance in your digestive system & 2 \\
\hline B7 & Contains essential omega-3 fatty acids, which may reduce your risk of heart disease & 2 \\
\hline $\mathrm{C} 2$ & A beverage you feel good about serving your family & 2 \\
\hline C6 & Even better for you than you thought & 2 \\
\hline D1 & From your favorite local dairy & 2 \\
\hline A5 & Crisp, light and refreshing & 1 \\
\hline B4 & With important micronutrients that enhance the body's immune function & 1 \\
\hline C3 & Fills that empty spot in you ... just when you want it & 1 \\
\hline D9 & Recommended by nutritionists and dieticians & 1 \\
\hline B6 & Contains the essential nutrient choline ... shown to improve memory and learning & -1 \\
\hline C5 & Calms you down ... just what you need when you are feeling stressed & -1 \\
\hline D2 & From Dean’s & -2 \\
\hline A3 & Indulgent flavors like rich and creamy chocolate and cookies in cream & -4 \\
\hline A7 & Skim Plus with $37 \%$ more protein & -5 \\
\hline A9 & $100 \%$ organic & -5 \\
\hline B5 & With inulin ... known to improve calcium absorption and improve digestion & -5 \\
\hline D4 & From Organic Valley & -7 \\
\hline D3 & From Lactaid & -8 \\
\hline B9 & Made with plant sterol esters ... clinically proven to lower cholesterol & -10 \\
\hline
\end{tabular}




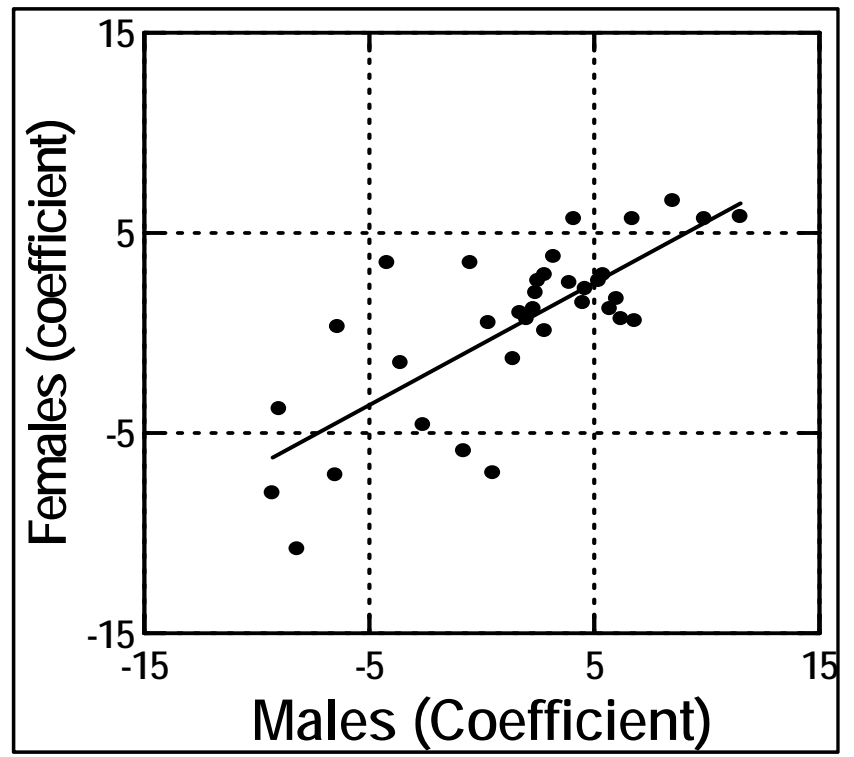

Fig. 1 Scatterplot showing the strong covariation between the average coefficients for the models estimated for males (abscissa) versus the average coefficients for the models estimated for females (ordinate). The Pearson correlation is highly significant, $+\mathbf{0 . 8 1}$ across the 36 corresponding coefficients. The line shows an estimate least squares fit, assuming a linear relation.

did show highly correlated coefficients. In turn, Table 3 shows the six pairwise Pearson correlation coefficients, reaffirming that these four segments behave quite independently.

\section{Predicting Segment Membership for New Individuals}

The scientific effort moves from experiment to identification of mind-sets. Beyond the scientific effort lies the practical world of application. When the researcher can assign a new person to one of the four segments, it becomes possible to study the co-variation of segment membership to either biological aspects (who the person is, biologically), to behavior (what the person does). It also becomes possible to send the person the "appropriate" messages, i.e., those messages relevant for the mind-set segment to which the person belong. This application has the promise of helping people to enjoy better nutrition because they are sent the proper messages about nutrition, viz. messages that are important to them, and messages to which they will respond positively.

Given the above opportunities, our next step is to put all these results into action and use to predict the segment membership of "new" respondents. The science behind Mind Genomics enables us to compare the regression coefficients of the obtained four segments, and, in turn, identify those elements which play a significant role in each. Then, these elements are compared based on so-called distance metrics. The most differentiating ones are chosen. We look for the elements which best describes and most effectively differentiates given segment from the others. At the end of the process, we create a short questionnaire (the so-called typing-tool or PVI (personal viewpoint identifier)) which assigns a new personal to the most likely segment, based on the answers assigned by the new individual who used the PVI. Fig. 3 shows the layout of the PVI for this study, and Fig. 4 shows one result emerging from the use of the tool. 
Table 3 Performance of the 36 messages by total panel and the four mind-set segments. The name for the segment is assigned by the researcher, and often comes from the commonality of the highest scoring elements for that segment. All coefficients with values higher than 7.51 are shown in shaded cells. The answers or elements are sorted to highlight the commonalities within a mind-set segment, and the differences across mind-set segments.

\begin{tabular}{|c|c|c|c|c|c|c|}
\hline & & Total & SegD1 & SegD3 & SegD2 & SegD4 \\
\hline & Base size & 248 & 111 & 51 & 49 & 37 \\
\hline & Constant & 44 & 48 & 25 & 43 & 61 \\
\hline & \multicolumn{6}{|l|}{ SegD1-Traditional + Health } \\
\hline A2 & A tall glass of delicious, ice cold milk, right from the fridge & 15 & 13 & 10 & 27 & 13 \\
\hline B1 & Provides essential nutrients for bone health, including calcium and vitamin D & 7 & 9 & 15 & -2 & 2 \\
\hline C9 & May reduce your risk of high blood pressure and stroke & 7 & 8 & 12 & 3 & 1 \\
\hline \multirow[t]{2}{*}{ C7 } & Builds and maintains strong bones & 6 & 8 & 8 & 3 & 2 \\
\hline & \multicolumn{6}{|l|}{ SegD3-Traditional + Healthful Essentials } \\
\hline B7 & Contains essential omega-3 fatty acids, which may reduce your risk of heart disease & 2 & 1 & 20 & -15 & -1 \\
\hline B4 & With important micronutrients that enhance the body’s immune function & 1 & 1 & 18 & -10 & -5 \\
\hline C8 & $\begin{array}{l}\text { As part of a low fat, low cholesterol diet, may reduce the risk of some forms of } \\
\text { cancer }\end{array}$ & 5 & 5 & 16 & 0 & -1 \\
\hline B2 & $\begin{array}{l}\text { Provides essential minerals your body needs, including potassium, magnesium, and } \\
\text { zinc }\end{array}$ & 2 & 1 & 14 & -6 & 2 \\
\hline B6 & Contains the essential nutrient choline ... shown to improve memory and learning & -1 & -2 & 14 & -8 & -13 \\
\hline A7 & Skim plus with $37 \%$ more protein & -5 & -20 & 13 & 2 & 8 \\
\hline B3 & With ingredients that restore and maintain a healthy balance in your digestive system & 2 & 4 & 11 & -11 & 0 \\
\hline A8 & All natural...no artificial flavors, no preservatives & 3 & 0 & 11 & 2 & 0 \\
\hline B5 & With inulin ... known to improve calcium absorption and improve digestion & -5 & -8 & 10 & -19 & 0 \\
\hline \multirow[t]{2}{*}{ B9 } & Made with plant sterol esters ... clinically proven to lower cholesterol & -10 & -13 & 9 & -27 & -5 \\
\hline & SegD2-Indulgent & & & & & \\
\hline A1 & Healthy drinking that tastes great & 7 & 7 & 5 & 16 & 0 \\
\hline A3 & Indulgent flavors like rich and creamy chocolate and cookies in cream & -4 & -4 & -3 & 15 & -32 \\
\hline A4 & Incredibly smooth and creamy & 2 & -2 & 2 & 12 & 3 \\
\hline \multirow[t]{2}{*}{ A5 } & Crisp, light and refreshing & 1 & -3 & 1 & 11 & 0 \\
\hline & SegD4—Listens to Authority & & & & & \\
\hline D8 & Recommended by your doctor & 3 & 2 & 1 & -1 & 12 \\
\hline D6 & Endorsed by the American Diabetes Association & 4 & 3 & 3 & 1 & 11 \\
\hline \multirow[t]{2}{*}{ D7 } & Endorsed by the American Dietetic Association & 3 & 1 & 3 & 1 & 10 \\
\hline & Do not strong apply to any of the four mind-sets & & & & & \\
\hline D9 & Recommended by nutritionists and dieticians & 1 & -1 & 4 & -4 & 6 \\
\hline D5 & Endorsed by the American Heart Association & 4 & 7 & 2 & -3 & 5 \\
\hline A6 & A full line of fresh milk & 3 & 2 & 2 & 7 & 4 \\
\hline C6 & Even better for you than you thought & 2 & 5 & -1 & -2 & 4 \\
\hline D1 & From your favorite local dairy & 2 & 3 & 2 & -1 & 3 \\
\hline $\mathrm{C} 4$ & Such pleasure ... knowing you are drinking something healthy & 3 & 3 & 2 & 4 & 3 \\
\hline $\mathrm{C} 2$ & A beverage you feel good about serving your family & 2 & 4 & 2 & -1 & 2 \\
\hline C3 & Fills that empty spot in you ... just when you want it & 1 & 0 & -2 & 7 & 0 \\
\hline C5 & Calms you down ... just what you need when you are feeling stressed & -1 & 3 & -8 & -1 & -1 \\
\hline $\mathrm{C} 1$ & A quick and easy way to get the nutrition you want & 3 & 3 & 4 & 4 & -1 \\
\hline A9 & $100 \%$ organic & -5 & -13 & 6 & -3 & -1 \\
\hline D4 & From Organic Valley & -7 & -11 & -5 & -4 & -3 \\
\hline D3 & From Lactaid & -8 & -12 & -5 & -7 & -4 \\
\hline B8 & An important natural source of protein & 3 & 3 & 7 & 2 & -4 \\
\hline D2 & From Dean’s & -2 & -3 & 1 & -2 & -5 \\
\hline
\end{tabular}




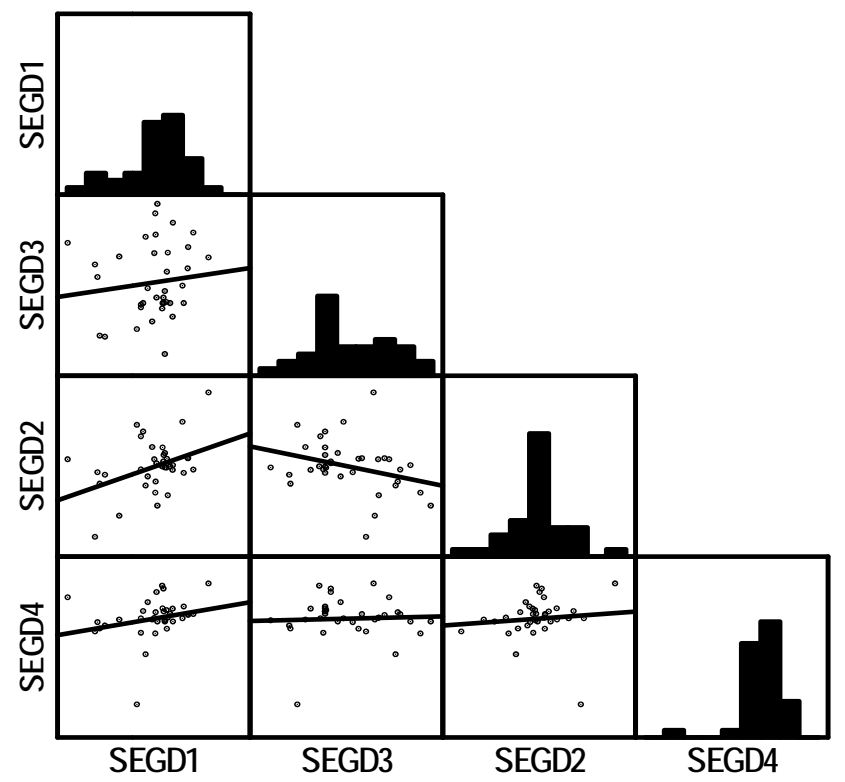

Fig. 2 Scatterplot matrix showing how the coefficients from the four mind-set segments co-vary with each other. The covariation is small. The line shows an estimate least squares fit, assuming a linear relation.

Table 4 Pearson correlation coefficients between pairs of mind-set segments for milk, and based upon the coefficients for the 36 elements.

\begin{tabular}{lllll}
\hline & SEGD1 & SEGD3 & SEGD2 & SEGD4 \\
\hline SEGD1 & 1.00 & & & \\
SEGD3 & 0.12 & 1.00 & & \\
SEGD2 & 0.40 & -0.31 & 1.00 & 1.00 \\
SEGD4 & 0.25 & 0.05 & 0.10 & \\
\hline
\end{tabular}

\begin{tabular}{|c|c|c|}
\hline \multicolumn{3}{|c|}{$\begin{array}{l}\text { Welcome to Shiny Typing Tool of study: } \\
\text { Weak signals and mind-sets of consumers: The case of milk }\end{array}$} \\
\hline \multicolumn{3}{|l|}{ How interested are you in this MLL? } \\
\hline $\begin{array}{l}\text { Contains the essential nutrient choline...shown to improve } \\
\text { memory and learning }\end{array}$ & not at all & extremaly \\
\hline Skim Plus with $37 \%$ more protein & notat all & extremely \\
\hline Recommended by your doctor & not at all & extremaly \\
\hline $\begin{array}{l}\text { Contains essential omega- } 3 \text { fatty acids, which may reduce } \\
\text { your risk of heart disease }\end{array}$ & not at all & extremely \\
\hline Provides essential nutrients for bone health, including & not at all & extremely \\
\hline Indulgent flavors like rich and creamy chocolate and cookies & not at all & extermaly \\
\hline \multicolumn{3}{|l|}{$\begin{array}{l}\text { Please provide your } \\
\text { email address. }\end{array}$} \\
\hline \multicolumn{3}{|c|}{ We will not share your e-mail address with third-parties and it will not be used for marketing purposes. } \\
\hline Submit & & \\
\hline
\end{tabular}

Fig. 3 The PVI for the milk study. 
Traditional + Health

This segment wants traditional and health, with the health being the calcium and vitamin $D$ for which milk is known

Fig. 4 Out of the PVI for one respondent.

\section{Conclusions}

These results suggest that much of what we see as trends in the food industry might well be discovered early, perhaps even before they become noticeable trends. The approach suggested here dimensionalizes the food experience into a set of questions, and, in turn, provides alternative answers to these questions. The respondents then evaluate combinations of these answers. From their answers, it becomes possible to determine the existence and nature of mind-sets, individuals who respond to different parts of the experience. The respondents may not even be aware of their individual proclivities, their mind-sets, but the experiment reveals these mind-sets.

This study revealed four mind-sets with respect to milk. There is a possibility that even smaller trends might exist for milk, trends that would be masked by extracting only four segments. One could extract five, six, even seven segments from these data, looking for a small-size mind-set segment, perhaps comprising $15-20$ respondents, or $10 \%$ of the population. This extraction of mind-sets provides an operational method to identify small, but possibly real weak signals in the environment, far earlier than other methods, and certainly before this small segment grows to be economically important.

\section{Acknowledgement}

AG thanks the support of Premium Postdoctoral Program of Hungarian Academy of Sciences.

\section{References}

[1] Gladwell, M. 2004. "Malcolm Gladwell on Spaghetti Sauce and Happiness." Retrieved from https://www.ted.com/talks/malcolm_gladwell_on_spaghe tti_sauce?language $=\mathrm{en}$.

[2] Moskowitz, H. 1998. Food Concepts and Products:
Just-in-Time Development (1st ed.). CRC Press.

[3] Brewer, J. L., Blake, A. J., Rankin, S. A., and Douglass, L. W. 1999. "Theory of Reasoned Action Predicts Milk Consumption in Women." Journal of the American Dietetic Association $99 \quad$ (1): 39-44. https://doi.org/https://doi.org/10.1016/S0002-8223(99)00 012-7.

[4] Saba, A., Moneta, E., Nardo, N., and Sinesio, F. 1998. "Attitudes, Habit, Sensory and Liking Expectation as Determinants of the Consumption of Milk.” Food Quality and Preference 9 (1): 31-41. https://doi.org/https://doi.org/10.1016/S0950-3293(97)00 024-4.

[5] Shepherd, R., Sparks, P., Bellier, S., and Raats, M. M. 1991. "The Effects of Information on Sensory Ratings and Preferences: The Importance of Attitudes.” Food Quality and Preference 3 (3): 147-55. https://doi.org/https://doi.org/10.1016/0950-3293(91)900 51-F.

[6] Lynchehaun, F., and Hill, H. 2002. "Organic Milk: Attitudes and Consumption Patterns.” British Food Journal $\quad 104 \quad$ (7): $526-42$. https://doi.org/10.1108/00070700210434570.

[7] MacFie, J. H., and Beharrell, B. 1991. "Consumer Attitudes to Organic Foods.” British Food Journal 93 (2): 25-30. https://doi.org/10.1108/00070709110002706.

[8] Klöckner, C. A., and Ohms, S. 2009. "The Importance of Personal Norms for Purchasing Organic Milk.” British Food Journal 111 (11): 1173-87. https://doi.org/10.1108/00070700911001013.

[9] Pedersen, S., Aschemann-Witzel, J., and Thøgersen, J. 2018. “Consumers' Evaluation of Imported Organic Food Products: The Role of Geographical Distance.” Appetite 130: 134-45. https://doi.org/https://doi.org/10.1016/j.appet.2018.08.016.

[10] Cox, D. N., Evans, G., and Lease, H. J. 2011. "The Influence of Product Attributes, Consumer Attitudes and Characteristics on the Acceptance of: (1) Novel Bread and Milk, and Dietary Supplements and (2) Fish and Novel Meats as Dietary Vehicles of Long Chain Omega 3 Fatty Acids." Food Quality and Preference 22 (2): 205-12.

https://doi.org/https://doi.org/10.1016/j.foodqual.2010.10. 003.

[11] Moskowitz, H., Porretta, S., and Silcher, M. 2005. Concept Research in Food Product Design and 
Development (1st ed.). Wiley-Blackwell.

[12] Porretta, S., Gere, A., Radványi, D., and Moskowitz, H. 2018. "Mind Genomics (Conjoint Analysis): The New Concept Research in the Analysis of Consumer Behaviour and Choice." Trends in Food Science and Technology,

in

Press. https://doi.org/10.1016/j.tifs.2018.01.004.

[13] Luce, R. D., and Tukey, J. W. 1964. "Simultaneous Conjoint Measurement: A New Type of Fundamental
Measurement.” Journal of Mathematical Psychology 1 (1): $1-27$. https://doi.org/10.1016/0022-2496(64)90015-X.

[14] Gofman, A., and Moskowitz, H. 2010. "Isomorphic Permuted Experimental Designs and Their Application in Conjoint Analysis.” Journal of Sensory Studies 25 (1): 127-45.

https://doi.org/10.1111/j.1745-459X.2009.00258.x. 